\title{
Life cycle energy and GHG emissions of PET recycling: change-oriented effects
}

\author{
Li Shen • Evert Nieuwlaar • Ernst Worrell • \\ Martin K. Patel
}

Received: 4 November 2010 / Accepted: 28 April 2011 /Published online: 20 May 2011

(C) The Author(s) 2011. This article is published with open access at Springerlink.com

\begin{abstract}
Purpose The demand of PET bottles has increased rapidly in the past decades. The purpose of this study is to understand the environmental impact of PET recycling system, in which used bottles are recycled into both fibre and bottles, and to compare the recycling system with single-use PET.

Methods Consequential LCA modelling was applied to understand four change-oriented effects for the recycling system. These include the effect of multiple-recycling trips, the effect of changing the share of recycled PET pellets used to make bottles or fibre, the effect of changing the reference system and the effect of introducing bio-based PET. The functional unit of the baseline case was determined as $350 \mathrm{~kg}$ of bottles and $650 \mathrm{~kg}$ of fibre based on the current market demand of PET. The system boundary is cradle to grave excluding the use phase. We applied the "system expansion" method to open-loop
\end{abstract}

Responsible editor: Hans-Jürgen Garvens

Electronic supplementary material The online version of this article (doi:10.1007/s11367-011-0296-4) contains supplementary material, which is available to authorized users.

L. Shen $(\bowtie) \cdot$ E. Nieuwlaar $\cdot$ M. K. Patel $(\bowtie)$

Department of Science, Technology and Society,

Faculty of Science, Utrecht University,

Utrecht, The Netherlands

e-mail: 1.shen@uu.nl

M.K. Patel

e-mail: m.k.patel@uu.nl

E. Worrell

Department of Innovation and Environmental Sciences,

Faculty of Geosciences, Utrecht University,

Utrecht, The Netherlands recycling. The analysis compares the baseline recycling system, where PET is recycled once, with the reference system, where PET is not recycled. The environmental impacts assessed are non-renewable energy use and global warming.

Results and discussion The baseline recycling system reduces both impacts by $20 \%$ when compared to the reference system. Multiple-recycling trips can maximally reduce the impacts by $26 \%$ but the additional savings are negligible after three recycling trips. Bottle-to-fibre recycling offers more impact reduction than bottle-tobottle recycling when more fibre is needed than bottles in a functional unit. The maximal impact reduction of $25 \%$ can be achieved when all recycled PET pellets are used to make fibre. If the functional unit is reversed, i.e. changed to $650 \mathrm{~kg}$ of bottles and $350 \mathrm{~kg}$ of fibre, $30 \%$ of the impact reduction can be achieved. Both impacts can be further reduced when the quantity of the recycled PET is maximised. The bio-based PET recycling system, offers at least $36 \%$ impact reduction, has the lowest impact among all systems studied. The sensitivity analyses show that the recycled PET content in a recycled bottle is not influential to the overall environmental performance.

Conclusions All PET recycling systems in this study show important impact reduction compared to the reference system. The impact savings are around $20-30 \%$ depends on the configurations of the recycling system. We conclude that the system's environmental impact can be optimised by maximising the amount of recycled PET in the system and by using bio-based polymers.

Keywords Bio-based PET - Change-oriented - LCA · PET . Recycling · Open-loop · Energy · Global warming · Packaging 


\section{Introduction}

The demand of bottle-grade PET (polyethylene terephthalate) has experienced two-digit growth rates in the past two decades (Glenz 2007), making PET the most important packaging plastic next to polyolefins (Simon and Schnieders 2009). Meanwhile, PET recycling has become a well-established business. Worldwide, in 2007, approximately $10 \%$ of used PET bottles were collected and recycled into 3.6 million tonnes of PET flakes (Thiele 2009). Approximately $72 \%$ of these PET flakes were converted into fibres, about $10 \%$ were converted into recycled bottles and $18 \%$ into other products (e.g. sheets and strapping tapes; Thiele 2009). It is expected that in the future more and more used bottles will be recycled back into bottles (Glenz 2007).

Many studies reported on the life cycle assessment (LCA) of PET recycling. Most of these studies were conducted in order to support the decision-making on waste management, e.g. recycling was compared with landfilling or incineration, or to optimise the recycling process (Arena et al. 2003; Perugini et al. 2004; Song and Hyun 1999; Song et al. 1999; Romero-Hernández et al. 2009). A few studies dealt with the impact of the recycled products where cases of open-loop and/or closed-loop recycling were analysed (Detzel et al. 2004; Shen et al. 2010; Van der Velden 2010). Despite the different goals of these studies, all of them concluded that recycling of PET reduces the environmental impact.

The goal of the present study is to gain further insights into PET recycling system, in which used bottles are recycled into both bottles and fibre, the two most important products of virgin and recycled PET. We studied the effects related to changes of the following four parameters in this open-loop recycling system: (a) the number or recycling trips, (b) the shares of recycled PET pellets used for B2B (bottle-to-bottle) and B2F (bottle-to-fibre) recycling, (c) the change of the market demand of bottle and fibre and (d) PET polymer made from bio-based feedstock. The motivations of studying these effects are stated as the following:

- In the previous LCA studies on PET recycling, the effect of multiple-recycling trips has not been discussed. The industry has grown fast and is likely to continue in the future (Glenz 2007). It is expected that the quantity of recycled PET will increase and the recycled polymer can be further recycled. We therefore formulate as our first research question: what is the effect of multiple-recycling trips on the overall environmental impact of PET recycling?

- The second parameter is related to the market demand of recycled PET pellets. Currently, about seven times more recycled PET pellets are used for recycled fibre than for recycled bottles (Thiele 2009). If more recycled PET pellets are available for B2B recycling, less of them would be available for fibres. The optimisation of $\mathrm{B} 2 \mathrm{~B}$ and $\mathrm{B} 2 \mathrm{~F}$ recycling should be studied to understand how the environmental impact can be minimised. The second research question of this study is: how does the overall environmental impact change when the share of recycled PET pellets used for $B 2 F$ and for $B 2 B$ recycling changes?

- Worldwide, in 2005, approximately $65 \%$ of the PET polymer was used to produce fibre and $30 \%$ was used to produce bottles (Glenz 2007). ${ }^{1}$ In contrast, in Europe, only about $35 \%$ of PET went into the fibre sector (Glenz 2007). It is interesting to investigate whether the share of the market demand of bottle and fibre influences the overall environmental impact of the recycling system. This leads to the third research question: how does the overall environmental impact change when the market demands of PET bottle and fibre change?

- The fourth parameter is related to bio-based feedstock. Bio-based plastics have attracted much attention in the past decades due to the concerns of limited fossil resources and climate change. Several studies have shown that bio-based materials have lower environmental impacts than their petrochemical counterparts (Crank et al. 2005; Hermann et al. 2007; Patel et al. 2003; Shen and Patel 2008; Patel et al. 2005). Biobased PET and petrochemical PET are chemically identical. A comparative LCA of recycled PET, biobased virgin PET and bio-based recycled PET has not been conducted so far. Our fourth research question is raised: how does recycled PET compare to bio-based virgin PET and bio-based recycled PET?

In LCA, the methodology of open-loop recycling has been extensively discussed but only a few case studies are available in the public domain. In our previous study (Shen et al. 2010), three allocation methods were applied to openloop recycling. The three methods are the "cut-off" method, "waste valuation" method and the "system expansion" method. All three methods have different perspectives and thus have different system boundaries. It was concluded that the "system expansion" method is the preferred choice because it implements the life-cycle thinking. In the present study, all four research questions are related to the effect of increased recycling in different forms. Therefore, we follow the principle of consequential LCA and apply the "system expansion" method. The details of the model are presented in Section 2. The environmental impacts analysed are non-

\footnotetext{
${ }^{1}$ The remaining $5 \%$ is used for other applications such as films and injection moulded products (Glenz 2007).
} 
renewable energy use (NREU) and global warming (i.e. impact on climate change). Section 3 shows the results. In Section 4, the sensitivities of the key assumptions are analysed. Section 5 concludes this study.

\section{Methodology}

\subsection{Functional unit and system boundary}

Considering that, in $2005,65 \%$ of all virgin PET was converted into fibres and 30\% into bottles (Glenz 2007), we defined the functional unit as $350 \mathrm{~kg}$ of PET bottles and $650 \mathrm{~kg}$ of PET fibre. Compared to the market shares, we increased the amount of PET bottles in the functional unit (from $30 \%$ to $35 \%$ of the total) in order to arrive at a total output of $1000 \mathrm{~kg}$.

In this study, the functionality of the virgin and recycled products is considered to be identical. In order to meet the regulations of food safety, the recycled PET bottle-grade resin is produced via super-clean recycling processes (Glenz 2007; Van der Velden 2010) and a recycled bottle should contain at least $65 \%$ of virgin PET, even in the case of repeated recycling trips (thus, a recycled bottle contains a maximum of $35 \%$ of recycled PET). This ratio is the practical maximum value because the discoloration effect is acceptable for commercial use (Kosior 2007; Van der Velden 2010).

Virgin PET fibre has a wider application spectrum than recycled PET fibre. Shen et al. (2010) distinguished the following three main differences: (1) PET fibres produced via mechanical recycling are mainly staple fibre, while virgin PET is converted into both staple and filament fibres; these two products serve different applications. (2) Recycled PET fibre cannot be used to produce microfibre. (3) The dyeability of recycled fibre is limited. In short, recycled PET fibre is mainly used in so-called technical applications, while virgin PET fibre can be used in technical applications, apparel and also high performance applications. This should be taken into account when using the results of this LCA.

The system boundary of this LCA is cradle to grave. Related transportation services (i.e. bottle waste collection, flake transportation and pellet transportation) were taken into account. Since the research questions are related to a system change, we applied consequential LCA modelling (or change-oriented LCA, prospective LCA) (Guinée 2001; Tillman 2000; European Commission 2010). Consequential LCA is used when comparing two (or more than two) systems to support decision-making. In the present study, we distinguished two product systems: the reference system and the recycling system. The reference system is a singleuse (or one-way) PET system. The use phases of PET bottles and fibre are identical for both reference and recycling systems and hence cancel out. Furthermore, the amount of PET that is extruded into fibre and blowmoulded into bottles is identical for both systems; for this reason, the impacts related to fibre extrusion and bottle blow-moulding cancel out and are consequently not included in this analysis (since this is a change-oriented analysis).

In this study, the "grave" refers to the ultimate end-oflife of a product. This means that the material is not recycled any further and is disposed of. Recycling is an intermediate step between different life cycle stages (see Fig. 1). This is different from many other LCA studies where recycling is also considered as the "grave". In this study, the ultimate "grave" is assumed to be municipal solid waste incineration (MSWI) with energy recovery. The recovery rate is $60 \%$ in primary energy terms (see Table 2 in Section 2.3).

We assumed both virgin and recycled PET products to be produced and disposed of in Western Europe. The inventory data were obtained based on the average technology level of mid- or late-2000s (see Section 2.3).

\subsection{Life cycle inventory modelling}

Figure 1 shows the flow diagram of the reference system and the baseline recycling system, which will be modified in subsequent change-oriented modelling. In the reference system, bottles and fibres are produced from virgin PET (V-PET) polymer and incinerated with energy recovery. In the baseline recycling system, bottles are produced from V-PET polymer. The recycling process started with bottle collection. It is assumed that the used bottles are recycled with a collection rate of $100 \%{ }^{2}$ and a material efficiency $(\eta)$ of $95 \%$ based on Shen et al. (2010) and van der Velden (2010). Based on today's global material flows for recycled PET it was assumed in the baseline recycling system that $88 \%$ of the recycled PET (R-PET) pellets is used for B2F recycling and $12 \%$ go to the B2B recycling. ${ }^{3}$ Since PET fibre cannot be

\footnotetext{
${ }^{2}$ According to Thiele (2009), only $10 \%$ of the used PET was collected worldwide in 2007. If we would include a low collection rate in the inventory modelling, the changing effect of the recycling system would be hardly visible, i.e. the majority of the impact would originate from the $90 \%$ virgin PET which is not recycled. Since the goal of the LCA is to understand the impact of PET recycling, 100\% collection rate is assumed here to be able to focus on the PET recycling system. ${ }^{3}$ According to Thiele (2009), in 2007 worldwide $72 \%$ of the PET flakes were used to produce fibre and $10 \%$ were used to produce bottles. In this study we assume all available R-PET are used for B2F and $\mathrm{B} 2 \mathrm{~B}$ recycling since fibre and bottles are the most important applications of PET. Thus the share of R-PET used for B2F is $72 /(72+$ $10) \times 100 \%=88 \%$; the share of R-PET goes to B2B recycling is $1-88 \%=12 \%$.
} 

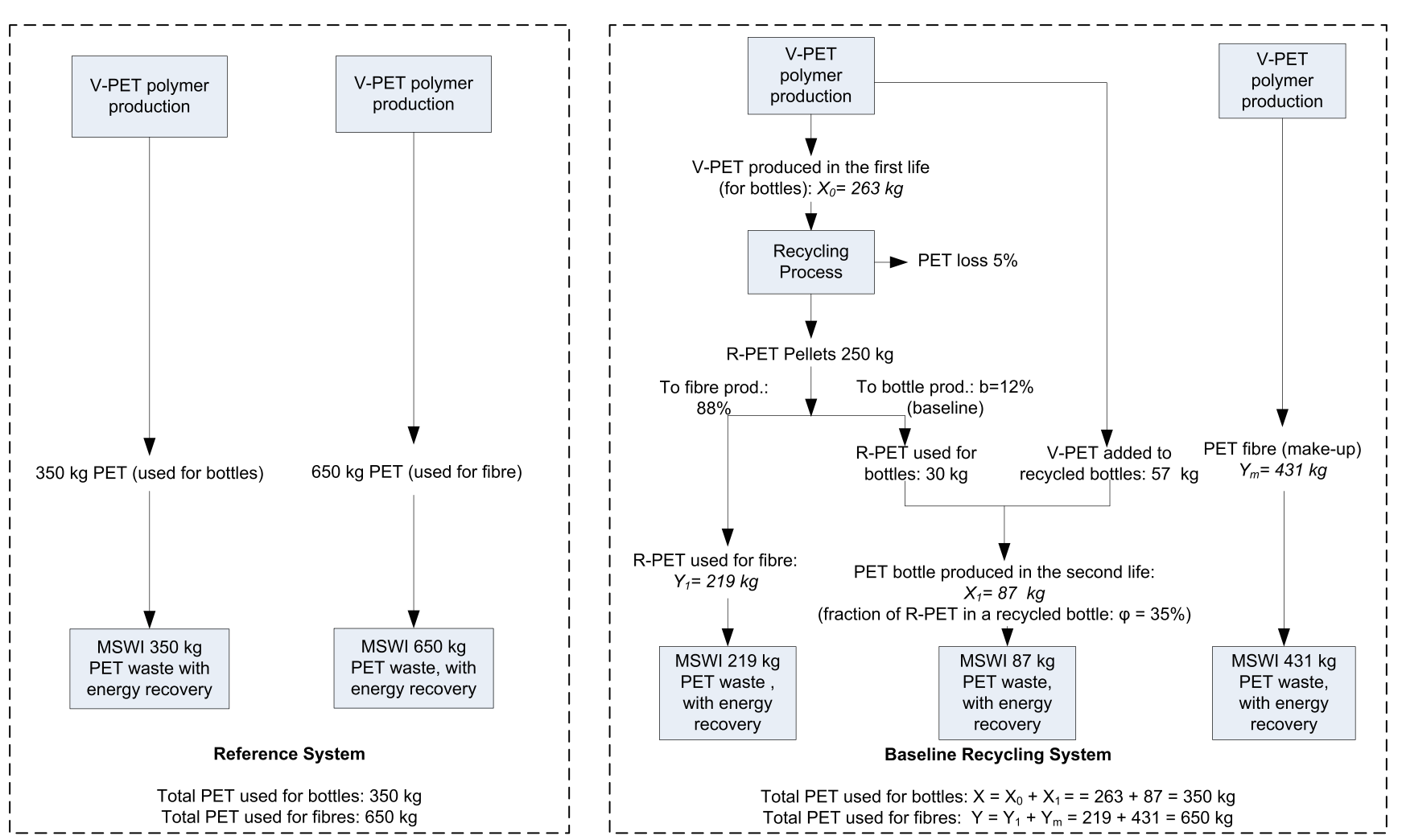

Fig. 1 Product systems: the baseline recycling system and the reference system (see the modelling in Eqs. 1, 2 and 3)

further recycled, ${ }^{4}$ the used fibre is disposed of in a MSWI plant with energy recovery. The R-PET pellets going to the $\mathrm{B} 2 \mathrm{~B}$ recycling are mixed with V-PET polymer in order to produce recycled bottles. In the current commercial practice, the maximum fraction of R-PET used in a recycled PET bottle $(\phi)$ is $35 \%$ (Kosior 2007; Van der Velden 2010). In the baseline recycling system, we assumed that the recycled bottles are not further recycled, although in theory it is possible to carry on the recycling. ${ }^{5}$ Here, used bottles from the second life are sent to a MSWI plant with energy recovery and the life cycle is completed. Figure 1 shows the baseline recycling system and the reference system.

Since the total amount of bottles delivered by the first life and the second life has to be $350 \mathrm{~kg}$, it can be

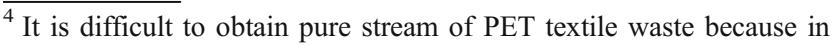
many cases PET fibres are blended with other textile fibres. Also, it is difficult to remove various additives, e.g., dyes and finishing chemicals, and to sort out a clean stream of PET. Furthermore, PET fibre has a relatively high crystallinity which further restricts mechanical recycling, although chemical recycling is possible; and it has been done (Patagonia 2005).

${ }^{5}$ This is not precisely in line with our earlier assumption of $100 \%$ collection rate (see footnote 2). However, the baseline case should be seen as the starting point of the analysis. Scenario 1 shows the analysis of multiple recycling trips, with $100 \%$ collection rate for each loop.
}

calculated that $263 \mathrm{~kg}$ of bottles are delivered in the first life and that $30 \mathrm{~kg}$ of recycled PET is combined with $57 \mathrm{~kg}$ of virgin PET to produce $87 \mathrm{~kg}$ of bottles in the second life (see Fig. 1). The amount of recycled fibre delivered in the second life is $219 \mathrm{~kg}$, which is less than the amount of fibre required for one functional unit. Here, we apply system expansion and make up $431 \mathrm{~kg}(=650-219)$ of virgin fibre for this product system. Thus, the amounts of PET bottle and fibre output in this recycling system are the same as those in the reference system. In the reference system, the total amount of incinerated post-consumer PET waste (bottle+fibre) is $1,000 \mathrm{~kg}$; while in the recycling system, the total amount post-consumer PET waste is $263 \mathrm{~kg}$ less, which is the amount of PET recycled.

Based on the baseline model, four scenarios were constructed in order to answer the four research questions. A summary of the four scenarios is shown in Table 1.

In Scenario 1, the effect of multiple-recycling loops was analysed. PET bottles are assumed to be recycled multiple times while all other parameters remain unchanged. The mass balance of bottles and fibres can be calculated with the following equations:

$X_{\mathrm{r}}=\sum_{i=0}^{n} X_{i}=X_{0} \times \sum_{i=0}^{n}\left(\frac{\eta b}{\varphi}\right)^{i}$ 
Table 1 Four scenarios in this study

\begin{tabular}{|c|c|c|c|c|c|}
\hline Changing parameters & $\begin{array}{l}\text { Baseline } \\
\text { Baseline } \\
\text { (current } \\
\text { situation) }\end{array}$ & $\begin{array}{l}\text { Scenario } 1 \\
\text { Multiple- } \\
\text { recycling } \\
\text { loops }\end{array}$ & $\begin{array}{l}\text { Scenario } 2 \\
\text { Change of the share of R-PET } \\
\text { pellets used for B2B recycling }\end{array}$ & $\begin{array}{l}\text { Scenario } 3 \\
\text { Change of PET fibre } \\
\text { and bottle demands }\end{array}$ & $\begin{array}{l}\text { Scenario } 4 \\
\text { Bio-based PET, and } \\
\text { recycled bio-based PET }\end{array}$ \\
\hline $\begin{array}{l}n \text { (number of recycling } \\
\text { trips) }\end{array}$ & 1 & $>1$ & $>1$ & $>1$ & 1 \\
\hline $\begin{array}{l}b \text { (share of R-PET pellets } \\
\text { used for B2B recycling) }\end{array}$ & $12 \%$ & $12 \%$ & $0-100 \%$ & $0-100 \%$ & $12 \%$ \\
\hline $\begin{array}{l}\text { Functional unit: Bottles/ } \\
\text { fibre }(\mathrm{kg})\end{array}$ & $350 / 650$ & $350 / 650$ & $350 / 650$ & $650 / 350$ & $350 / 650$ \\
\hline PET polymer & Petrochem. & Petrochem. & Petrochem. & Petrochem. & $\begin{array}{l}\text { Bio-based ethylene and } \\
\text { petrochem. PTA }\end{array}$ \\
\hline
\end{tabular}

$Y_{\mathrm{r}}=\sum_{i=0}^{n} Y_{i+1}=\sum_{i=0}^{n} \eta(1-b) \times X_{i}=\eta(1-b) X_{0} \times \sum_{i=0}^{n}\left(\frac{\eta b}{\varphi}\right)^{i}$

$X=X_{\mathrm{r}}+X_{\mathrm{m}} \quad Y=Y_{\mathrm{r}}+Y_{\mathrm{m}}$

Where:

$X \quad$ Total amount of bottle per functional unit.

$Y \quad$ Total amount of PET fibre per functional unit.

$X_{0} \quad$ Amount of V-PET bottle produced in the first life.

$X_{\mathrm{r}} \quad$ Total amount of bottle delivered from the recycling system, including the first-life bottles and all recycled bottles, excluding V-PET used for bottle make-up.

$Y_{\mathrm{r}} \quad$ Total amount of fibre delivered from the recycling system, including all recycled fibre, excluding V-PET for fibre make-up.

$X_{\mathrm{m}} \quad$ V-PET added to make up the bottle requirement of one functional unit. If $X_{\mathrm{r}}=X$, then $X_{\mathrm{m}}=0$ (see Fig. 1).

$Y_{m} \quad$ V-PET added to make up the fibre requirement of one functional unit. If $Y_{\mathrm{r}}=Y$, then $Y_{\mathrm{m}}=0$ (see Figs. 1 and 2).

$b \quad$ The share of R-PET pellets used for B2B recycling; in the baseline case $b=12 \%$ (see Fig. 1 ).

$\eta \quad$ Material efficiency of PET bottle-to-pellet recycling; $\eta=95 \%$ (see Table 2).

$\varphi \quad$ Fraction of R-PET used in a recycled bottle; V-PET required is $(1-\varphi) ; \varphi=35 \%$ (see Table 2 ).

$n \quad$ Number of recycling trips.

From Eq. 1, it can be seen that $\Sigma X_{i}$ is an infinite geometric series. Since the value of the common ratio $(b \times \eta / \varphi)$ is less than $1,{ }^{6}$ it is possible to calculate the finite sum provided that $i$ is large enough:

\footnotetext{
${ }^{6}$ Take the values of $b, \eta$ and $\varphi$ from Fig. $1: \eta b / \varphi=12 \% \times$ $95 \% / 35 \% \approx 0.33<1$
}

$\sum_{i=0}^{\infty} X_{i}=X_{0} \times \sum_{i=0}^{\infty}\left(\frac{\eta b}{\varphi}\right)^{i}=\frac{X_{0}}{1-(\eta b / \varphi)}$

In Scenario 2, the effect of using different shares of the available R-PET pellets for making bottles was analysed. In the baseline case, $12 \%$ of the R-PET obtained from the previous life is used to produce bottles (i.e. $b=12 \%$ ); and the remaining $88 \%$ is used to produce fibre. In this scenario, $\mathrm{b}$ is changed from $0 \%$ (i.e. all R-PET pellets are used for B2F recycling) to 100\% (i.e. all R-PET pellets are used for B2B recycling). Furthermore, the change of the environmental impact related to the change of $b$ is analysed for multiple-recycling trips (i.e. $n>1$ ).

In Scenario 3, the functional unit was changed into $650 \mathrm{~kg}$ of bottles and $350 \mathrm{~kg}$ fibre (i.e. the quantities of bottle and fibre are inversed but the total demand of PET does not change) while other parameters remain unchanged in relation to Scenario 2. Figure 2 shows the material flow of this scenario. In contrast to the baseline case, V-PET is needed for bottle make-up instead of fibre. Additionally, we also investigate the effect of changing parameter $b$ (i.e., $b=0-100 \%$ ), as well as the effect of multiple-recycling trips (i.e. $n>1$ ) with the new functional unit.

In Scenario 4, the effect of renewably sourced PET is studied. We change the data for the cradle-to-factory gate polymer production while all other parameters remain the same as in the baseline case. In this scenario, bio-based PET is produced from bio-based EG (ethylene glycol) and petrochemical PTA (purified terephthalic acid); strictly speaking we are hence studying partially bio-based PET. Bio-based EG is produced from bio-based ethylene which is the dehydration product of bio-based ethanol. Currently, the two most important bio-based feedstocks of ethanol production are sugarcane and maize. ${ }^{7}$ We assume that the

\footnotetext{
${ }^{7}$ The US and Brazil are the two biggest fuel ethanol producing countries in the world. In 2009, the sum of the fuel ethanol production in the two countries accounted for nearly $90 \%$ of the world fuel ethanol production (RFA 2010). Fuel ethanol is produced from maize in the US and from sugarcane in Brazil.
} 

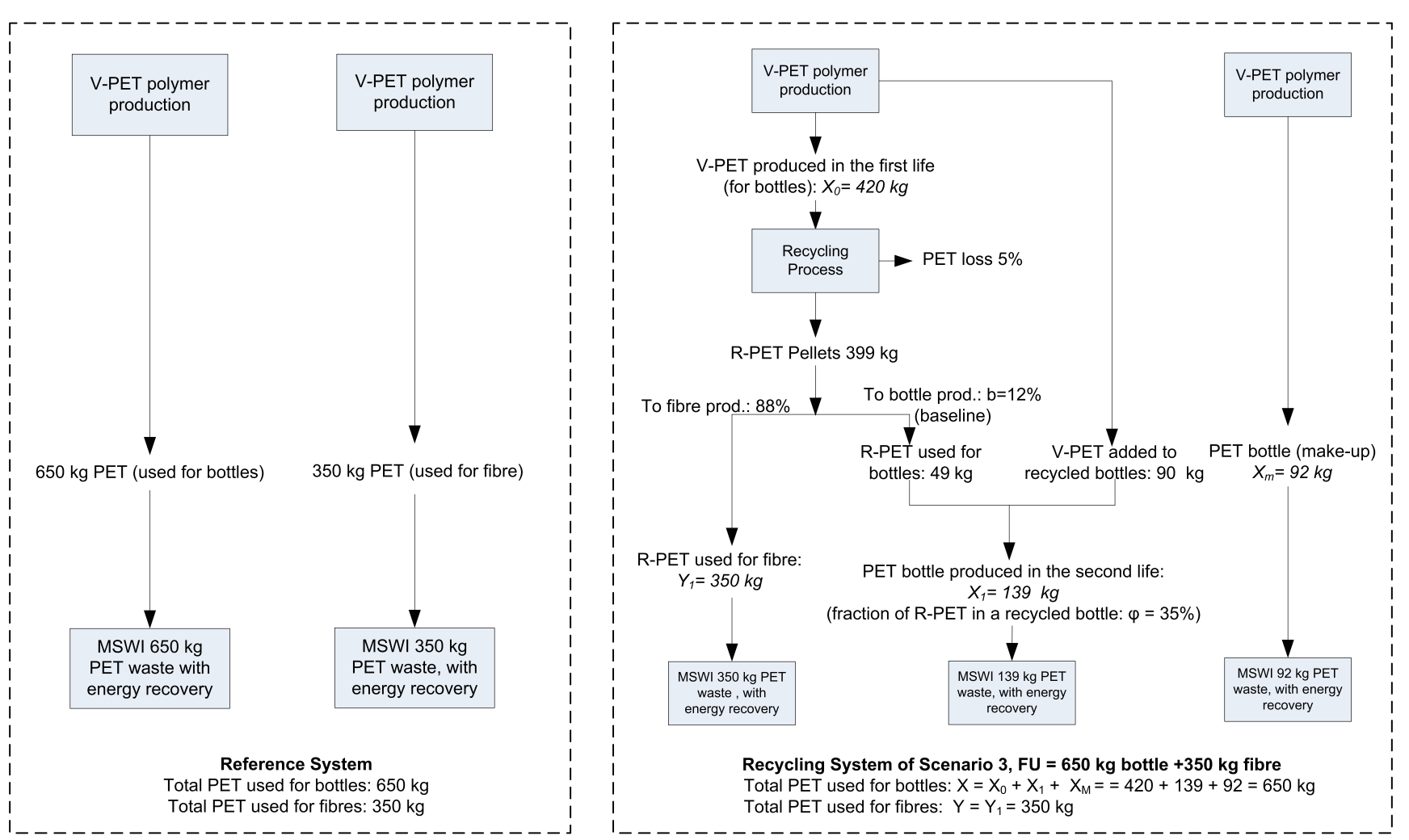

Fig. 2 Product systems of Scenario 3, functional unit: $650 \mathrm{~kg}$ bottle $+350 \mathrm{~kg}$ fibre

bio-based ethylene in this study is produced from $50 \%$ maize-based ethanol and 50\% sugarcane-based ethanol. The detailed data used to calculate the impact of bio-based PET can be found in Section 2.3. We assume petrochemical PTA because there is no commercially available bio-based equivalent.

\subsection{Input data}

The cradle-to-factory gate impact of virgin PET was acquired from the latest eco-profiles published by PlasticsEurope; the data represents the average technology in Western Europe in the late 2000s (Liebich and Giegrich 2010, see Section 3.5 for the discussion on the former PlasticsEurope's eco-profile). The inventory data of PET bottle-to-pellet recycling were based on literature data, most of which have been cross-checked with industrial experts. Other background data, such as road transportation and grid power generation, were obtained from the Ecoinvent database (Version 2.0). A summary of data and assumptions is shown in Table 2.

\subsection{Environmental impact categories: NREU and global warming}

NREU is the sum of cumulative fossil energy and nuclear energy (Frischknecht et al. 2004). Cumulative fossil energy is a good proxy of the environmental performance of many products (Huijbregts et al. 2006), although it is not a suitable proxy for all impacts, especially impacts related to land use and water use. The impact on global warming is calculated based on the characterisation factor of global warming potential based on IPCC guidelines with the timeframe of 100 years (IPCC 2007). For bio-based PET, the biogenic carbon embedded in the polymer is taken into account as negative GHG emissions for the system cradle to factory gate (BSI 2008). Consequently, in the "grave" stage, the biogenic $\mathrm{CO}_{2}$ released from the combustion of PET are added to the cradle-to-grave GHG emissions.

\section{Results}

\subsection{The baseline case}

Figure 3 shows that both NREU and global warming of the baseline recycling system are approximately $20 \%$ lower compared to the reference system. The impact reductions are mainly attributed to the decrease in V-PET fibre requirement, which is $650 \mathrm{~kg}$ in the reference system and $431 \mathrm{~kg}$ in the recycling system (see Fig. 1). The decrease of V-PET for bottles is not as significant as for fibre. Only $30 \mathrm{~kg}$ (or 9\%) of V-PET bottle are saved by the recycling system. As a result, the NREU and global warming impact 
Table 2 Summary of data used in this study

\begin{tabular}{|c|c|c|c|}
\hline Parameters & Value & Unit & Source \\
\hline $\begin{array}{l}\text { Virgin PET amorphous grade } \\
\text { NREU (non-renewable energy } \\
\text { use) }\end{array}$ & 66.64 & $\mathrm{MJ} / \mathrm{kg}$ & $\begin{array}{l}\text { Based on PlasticsEurope (Liebich and Giegrich 2010), the NREU and GHG } \\
\text { emissions (100 years) of PET bottle-grade are } 68.6 \mathrm{MJ} / \mathrm{kg} \text { and } 2.15 \mathrm{~kg} \mathrm{CO}_{2} \text { eq./ } \\
\mathrm{kg} \text {. Based on Boustead (2005a; 2005b), the NREU and Global warming }\end{array}$ \\
\hline Global warming (100 years) & 2.05 & $\mathrm{~kg} \mathrm{CO}_{2}$ eq. $/ \mathrm{kg}$ & $\begin{array}{l}\text { (100 years) of the SSP step (solid state polymerisation) are } 1.96 \mathrm{MJ} / \mathrm{kg} \text { and } \\
0.10 \mathrm{~kg} \mathrm{CO} 2 \text { eq. } / \mathrm{kg} \text {. The NREU and Global warming impact of PET amorphous } \\
\text { are calculated: } 68.60-1.96=66.64 \mathrm{MJ} / \mathrm{t} \text { and } 2.15-0.10=2.05 \mathrm{~kg} \mathrm{CO}_{2} \text { eq. } / \mathrm{kg} \text {. }\end{array}$ \\
\hline $\begin{array}{l}\text { Transportation distance, bottle } \\
\text { waste collection }\left(\mathrm{d}_{1}\right)\end{array}$ & 400 & $\mathrm{~km}$ & Assumed; to be checked in the sensitivity analysis. \\
\hline $\begin{array}{l}\text { Energy use for bottle sorting, } \\
\text { compacting and baling }\end{array}$ & Negligible & - & Assumed based on (Shen et al. 2010; Arena et al. 2003; Detzel et al. 2004) \\
\hline \multicolumn{4}{|l|}{ PET bottle-to-flake production: } \\
\hline Baled PET bottle waste & 1,316 & $\mathrm{~kg} / \mathrm{t}$ flake & Arena et al. (2003) \\
\hline Electricity & 278 & $\mathrm{kWh} / \mathrm{t}$ flake & Arena et al. (2003) \\
\hline Heat (from natural gas) & 2,500 & $\mathrm{MJ} / \mathrm{t}$ flake & Arena et al. (2003) \\
\hline $\mathrm{NaOH}(30 \%)$ & 10 & $\mathrm{~kg} / \mathrm{t}$ flake & Arena et al. (2003) \\
\hline Sulphuric acid $(30 \%)$ & 20 & $\mathrm{~kg} / \mathrm{t}$ flake & Arena et al. (2003) and Shen et al. (2010) \\
\hline By-products (e.g. PE) & 88 & $\mathrm{~kg} / \mathrm{t}$ flake & Arena et al. (2003) \\
\hline Allocation factor of by-products & $5 \%$ & - & Economic allocation (Arena et al. 2003; Shen et al. 2010) \\
\hline Solid waste ${ }^{\mathrm{a}}$ & 222 & $\mathrm{~kg} / \mathrm{t}$ flake & Arena et al. (2003) \\
\hline $\begin{array}{l}\text { Transportation distance, flake to } \\
\text { pellet production }\left(\mathrm{d}_{2}\right)\end{array}$ & 400 & $\mathrm{~km}$ & Assumed; to be checked in the sensitivity analysis \\
\hline \multicolumn{4}{|l|}{ Pellet production } \\
\hline Flakes input & 1,031 & $\mathrm{~kg} / \mathrm{t}$ pellet & Shen et al. (2010) \\
\hline Heat (from natural gas) & 252 & $\mathrm{MJ} / \mathrm{t}$ pellet & Bhatt (2008) \\
\hline Pellet extrusion & 447 & $\mathrm{kWh} / \mathrm{t}$ pellet & Kent (2008) \\
\hline $\begin{array}{l}\text { Material efficiency of PET (PET } \\
\text { bottle-to-pellet, PET flow, } \eta \text { ) }\end{array}$ & $95 \%$ & & $\begin{array}{l}\text { Assumed based on Shen et al. (2010) and Van der Velden (2010); to be } \\
\text { checked in the sensitivity analysis }\end{array}$ \\
\hline Fraction of R-PET pellet $(\phi)$ & $35 \%$ & & $\begin{array}{l}\text { Assumed based on Van der Velden (2010); to be checked in the sensitivity } \\
\text { analysis }\end{array}$ \\
\hline \multicolumn{4}{|l|}{ MSWI plant with energy recovery: } \\
\hline Gross calorific value of PET & 23 & $\mathrm{MJ} / \mathrm{kg}$ in & Ecoinvent Database Version 2.0 (Doka 2007) \\
\hline $\begin{array}{l}\text { Energy recovery from MSWI in } \\
\text { Western Europe }\end{array}$ & $60 \%{ }^{\mathrm{b}}$ & $\begin{array}{l}\text { primary energy } \\
\text { terms }\end{array}$ & $\begin{array}{l}\text { Reimann (2006) and Personal communication with Dr. Reimann; to be } \\
\text { checked in the sensitivity analysis. }\end{array}$ \\
\hline \multicolumn{4}{|l|}{ Bio-based PET } \\
\hline $\begin{array}{l}\text { - Bio-based EG } \\
\text { NREU }\end{array}$ & 17 & $\mathrm{MJ} / \mathrm{kg} \mathrm{EG}$ & $\begin{array}{l}\text { Chen and Patel (Forthcoming): no land use change is assumed for maize and } \\
\text { sugarcane production in the US and Brazil. Values reported in this table are }\end{array}$ \\
\hline Global warming (100 years) & $-0.55^{\mathrm{c}}$ & $\begin{array}{l}\mathrm{kg} \mathrm{CO} \mathrm{CO}_{2} \text { eq. } / \mathrm{kg} \\
\mathrm{EG}\end{array}$ & based on $50 \%$ maize and $50 \%$ sugarcane as the feedstock. \\
\hline - Petrochemical PTA & & & PlasticsEurope (Liebich and Giegrich 2010) \\
\hline NREU & 53 & $\mathrm{MJ} / \mathrm{kg}$ PTA & \\
\hline Global warming (100 years) & 1.33 & $\begin{array}{l}\mathrm{kg} \mathrm{CO} \\
\text { PTA eq. } / \mathrm{kg}\end{array}$ & \\
\hline - Polymerization & & & Patel et al. (1999) \\
\hline Natural gas & 2.29 & $\mathrm{GJ} / \mathrm{t}$ PET & \\
\hline Electricity & 101 & $\mathrm{kWh} / \mathrm{t} \mathrm{PET}$ & \\
\hline Steam & 240 & kg/t PET & \\
\hline PTA & 867 & $\mathrm{~kg} / \mathrm{t}$ PET & \\
\hline EG & 334 & $\mathrm{~kg} / \mathrm{t}$ PET & \\
\hline
\end{tabular}

Data obtained from the Ecoinvent database version 2.0

Transportation by road

Heat from natural gas

Process names in the Ecoinvent database

"Transportation, >32 t lorry, EURO3/RER"

"Heat, natural gas, at industrial furnace low-NOx $>100 \mathrm{~kW} / \mathrm{RER}$ " 
Table 2 (continued)

\begin{tabular}{|c|c|c|}
\hline Parameters & Value & Source \\
\hline EU grid electricity mix ${ }^{d}$ & & "Electricity, low voltage, production [grid name], at grid/[grid name]" \\
\hline $\mathrm{NaOH}$ & & "Sodium hydroxide, $50 \%$ in water, Production mix, at plant/RER" \\
\hline Sulfuric acid & & "Sulphuric acid, liquid, at plant/RER" \\
\hline Nitrogen & & "Nitrogen, liquid, at plant/RER" \\
\hline MSWI of PET & & "Disposal, polyethylene, $0.4 \%$ water, to municipal incineration/CH" \\
\hline
\end{tabular}

${ }^{a}$ Solid waste is sent to a MSWI plant with energy recovery

${ }^{\mathrm{b}}$ The efficiencies of electricity and heat are $10.6 \%$ and $22.3 \%$ in an average MSWI plant in Europe according to Reimann (2006). This means that $1 \mathrm{GJ}$ waste yields $0.106 \mathrm{GJ}_{\mathrm{e}}$ (electricity) and $0.223 \mathrm{GJ}_{\mathrm{th}}$ (heat). These amounts of electricity and heat would be otherwise produced conventionally with an electricity efficiency of $30 \%$ and a heat efficiency of $85 \%$ (assumed). Thus, $0.106 \mathrm{GJ}_{\mathrm{e}}$ electricity replaces $0.106 / 30 \%=0.35 \mathrm{GJ}_{\mathrm{p}}$ primary fossil fuels and $0.223 \mathrm{GJ}_{\text {th }}$ heat replaces $0.223 / 85 \%=0.26 \mathrm{GJ}_{\mathrm{p}}$ primary fossil fuels. The total primary fossil fuel that can be avoided is $0.35 \mathrm{GJ}_{\mathrm{p}}+0.26 \mathrm{GJ}_{\mathrm{p}}=0.61 \mathrm{GJ}_{\mathrm{p}}$ - this is approximately $60 \%$ of the energy content of the waste

${ }^{\mathrm{c}}$ Bio-based carbon has been considered as negative $\mathrm{CO}_{2}$ emissions. See Section 2.4 for the method of GWP

${ }^{\mathrm{d}}$ European electricity mix: $65 \%$ from the UCTE grid, 13\% from the NORDEL grid, $9 \%$ from the CENTREL grid, $12 \%$ from the UK grid and $1 \%$ from the Irish grid. UCET is Union for the Co-ordination of Transmission of Electricity; countries included in UCTE are Austria, Bosnia and Herzegovina, Belgium, Switzerland, Germany, Spain, France, Greece, Croatia, Italy, Luxemburg, Macedonia, Netherlands, Portugal, Slovenia and Serbia and Montenegro. NORDEL is Nordic countries power association, including Denmark, Norway, Finland and Sweden. CENTREL stands for Central European power association, including Czech Republic, Hungary, Poland and Slovakia

are both reduced by only approximately $9 \%$. Moreover, the recycling process, which converts $263 \mathrm{~kg}$ of used bottles (i.e. first-life V-PET bottles) into $250 \mathrm{~kg}$ of R-PET pellets, has a minor contribution to the overall impact of the recycling system. The NREU of the $250 \mathrm{~kg}$ of R-PET pellets is about 2.4 GJ (including recycling process, excluding the feedstock energy), which is only one-fourth of the NREU required to produce the same amount of V-PET pellets (excluding feedstock energy). Both systems receive energy credits and GHG-emission penalties from the combustion of post-consumer (PC) waste in an MSWI with energy recovery (ER). The baseline case saves a total amount of PC waste of $263 \mathrm{~kg}$ (i.e., the same amount as the first-life V-PET bottles), which results in a lower impact on global warming; these savings are slightly compensated by the lower energy credits.

\subsection{Scenario 1: multiple-recycling trips - effect of $n$}

Figure 4 demonstrates that if the number of recycling trips (n) increases, both NREU and global warming decrease dramatically until $n$ is equal to four. After four recycling trips, both impacts remain constant. This pattern reflects the property of the geometric series when the common ratio is less than one (see Eq. 1). If the recycling would be carried on for infinite times, the NREU and global warming would decrease to a marginally lower value, i.e. to $39.5 \mathrm{GJ} /$ functional unit and $2.58 \mathrm{t} \mathrm{CO}_{2}$ eq./functional unit, representing the maximal NREU and GHG-emission savings of $26 \%$ and $23 \%$ compared to the reference system. Four and more cycles hence allows to increase the NREU and GHG- emission savings by a maximum of six percentage points compared to the baseline recycling system.

\subsection{Scenario 2: change the share of R-PET pellets used for B2B recycling - effect of $b$}

In the baseline recycling system, $12 \%$ of the bottle waste is used for B2B recycling $(b=12 \%)$. If more R-PET pellets are used for B2F recycling (i.e. decreasing $b$ ), the overall impacts decrease (Fig. 5). When all R-PET pellets are used for $\mathrm{B} 2 \mathrm{~F}$ recycling (i.e. $b=0 \%$ ), NREU and global warming decrease by approximately $27 \%$ and $24 \%$ compared to the reference case. When $b$ is decreased to $0 \%$, the environmental impacts of the recycling system do not change with the number of recycling trips ( $n$; see Fig. 5), because the first-life virgin bottles are all converted into recycled fibre and fibre cannot be further recycled. If more R-PET pellets are used for $\mathrm{B} 2 \mathrm{~B}$ recycling (i.e. increasing $b$ ), the overall impacts increase (see Fig. 5). When all R-PET pellets are used for B2B recycling (i.e. $b=100 \%$ ) and after four recycling trips (i.e. $n>4$ ), the NREU and global warming decrease only about $10 \%$ compared to the reference case.

These dependencies can be understood by breaking down the mass balance of the system. Table 3 shows such a breakdown for one recycling trip $(n=1)$. When more R-PET pellets are used for B2B recycling (i.e. with increasing value of $b$ ), the amount of V-PET used for first-life bottles decreases, lowering the impact of V-PET used for first-life bottles. However, this also leads to less recycled PET fibre. Consequently, the system requires more V-PET for fibre make-up in order to fulfil the demand. The 

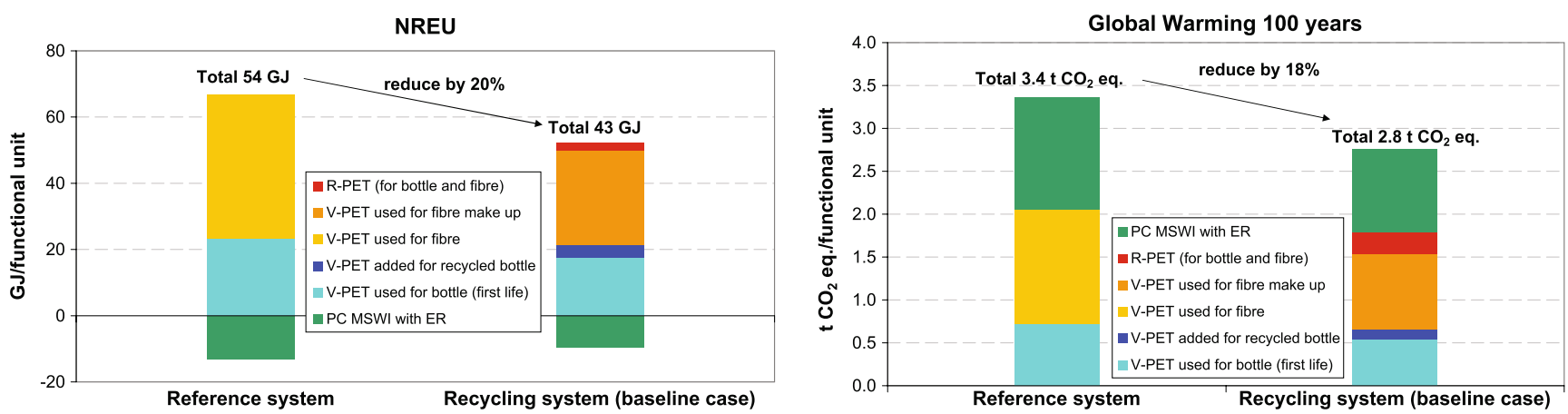

Fig. 3 Cradle-to-grave NREU (left) and global warming (right) of the baseline recycling system and the reference system

increase of V-PET used for fibre increases the total V-PET requirement. As shown in Table 3, the total V-PET requirement increases from $67 \%$ of the system's total material requirements when $b=0 \%$, to $91 \%$ when $b=$ $100 \%$. In addition, less V-PET used for first-life bottles also leads to less recycled PET in the system, resulting in more PC waste at the end-of-life stage.

Based on the analysis of this Scenario, we conclude that the environmental benefit of B2F recycling is greater than $\mathrm{B} 2 \mathrm{~B}$ recycling, when the demand of fibre is higher than the demand of bottle. This is caused by a larger total amount of R-PET produced in the B2F system than in the B2B system. In other words, if the market does not require many bottles, increasing the amount of B2B recycling does not bring additional environmental benefits. In Scenario 3, we will further discuss the change of the environmental impact based on a different market demand.

3.4 Scenario 3: change the demand of PET fibre and bottle (functional unit $=650 \mathrm{~kg}$ bottle and $350 \mathrm{~kg}$ fibre)

As explained earlier, the functional unit was defined based on the current market demand of PET (see Section 2.1). However, the PET market varies considerably in different regions. For example, in Asia, over $80 \%$ of the PET polymer was used to produce fibre in 2005 (Glenz 2007). In

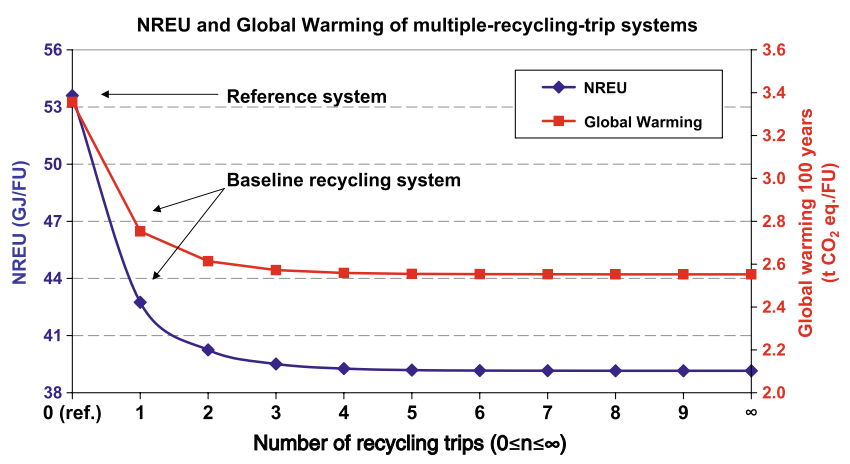

Fig. 4 Cradle-to-grave NREU and global warming of multiplerecycling-trip systems in Scenario 1 this scenario, we intend to understand how the change of PET demand can influence the environmental impact of the recycling system. We now change the reference system, assuming the inversed case where the demand of fibre is less than PET bottle, i.e. the functional unit is defined as $650 \mathrm{~kg}$ of PET bottle and $350 \mathrm{~kg}$ of PET fibre. The results of NREU and global warming are shown in Fig. 6.

In this scenario, the recycling system reduces NREU and global warming by approximately $30 \%$ compared to the reference system. The impact reductions of the recycling system in this scenario are larger than those of the baseline recycling case and also larger compared to all scenarios discussed above. The reason is that the quantities of R-PET are larger than those of the systems discussed above, i.e., $400 \mathrm{~kg}$ (or $40 \%$, see Table 4) as compared to $249 \mathrm{~kg}$ (or $25 \%$ ) in the baseline recycling system and a maximum of $333 \mathrm{~kg}$ (or $33 \%$ ) in Scenario 2 (see Table 3 when $b=0 \%$ ). More R-PET leads to less V-PET required in the system, which substantially reduces the impact (see Fig. 6). In the recycling system, no V-PET is required for fibre-making, i.e., the $350 \mathrm{~kg}$ of fibre is $100 \%$ produced from R-PET. Figure 6 also shows that the savings from the V-PET bottles are not significant. Only 7\% of the V-PET bottle is saved by recycling. And 1/7th of the total V-PET are used for the bottle make-up purpose.

It should be noted that this scenario implies that virgin fibre production is not needed anymore when B2B recycling is not more than $17 \%$ (i.e. $b \leq 17 \%$ ). In reality, while recycled PET fibre can partly replace virgin PET fibre, $100 \%$ substitution is rather unlikely. The functional equivalence of V-PET and R-PET bottles and fibres has been discussed in Section 2.1.

Furthermore, it should be emphasised that the reference system in this Scenario is not comparable with the reference system in the baseline recycling case because the functional units differ. Both reference systems have the same amount of impacts (compare Fig. 4 with Fig. 3) only because the fibre extrusion and bottle blow-moulding steps are cancelled out in the consequential LCA modelling. If fibre extrusion and bottle blow-moulding processes were included, the reference system in Scenario 3 would result in a 

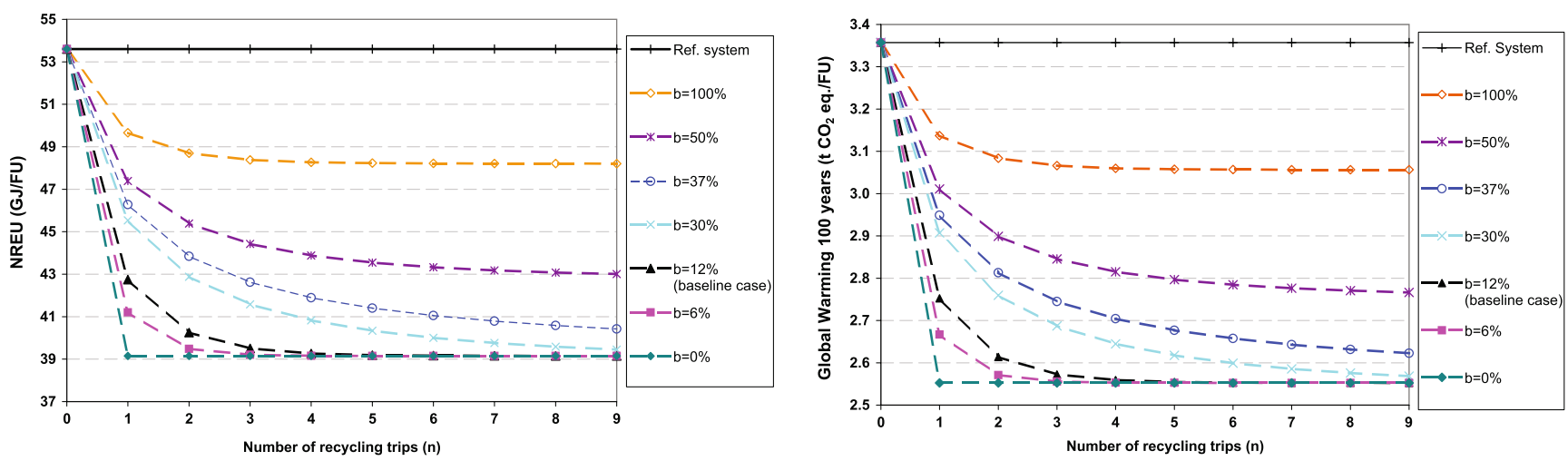

Fig. 5 Scenario 2: Effects of changing the share of recycled PET pellets used for B2B recycling (b) (left NREU, right global warming)

higher impact than the reference system in the baseline recycling case because bottle-making is more energy intensive than fibre-making. ${ }^{8}$ The comparison between the baseline recycling case and this scenario should be strictly about the consequence of recycling: impact reduction.

In Scenario 2, we found that the overall environmental impact of the recycling system is sensitive to the share of R-PET pellet used for B2B recycling (b) (see Fig. 5). In Scenario 3, the overall environmental impact is also sensitive to the value of $b$, but in a different way. Figure 7 shows that with one recycling trip (i.e. $n=1$ ), both NREU and global warming reach the lowest point when $b$ is $17 \%$. The breakdown of mass balance (see Table 4 ) indicates that when $b$ is $17 \%$, no make-up V-PET is required. ${ }^{9}$ The amount of R-PET produced in the recycling system is maximised (42\%). As a result, the impact of the recycling system is minimised. When $b$ is less than $17 \%$, V-PET is needed to make up the demand of bottles; when $b$ is more than $17 \%$, V-PET is needed to make up the demand of fibre. Either way of make-up increases the V-PET requirements and reduces the R-PET produced in the system, which in turn increases the overall impact. If more recycling trips are assumed (i.e. $n>1$ ), similar patterns can be observed. In Fig. 7 the minimal impact of the recycling system are observed when b is $26 \%, 31 \%$ and $33 \%$ (with $n=2$,

\footnotetext{
${ }^{8}$ The NREU and GHG emissions of converting amorphous PET into $1 \mathrm{t}$ of fibre are about $13 \mathrm{GJ}$ and $0.7 \mathrm{t} \mathrm{CO}_{2}$ eq. (calculated based on Brown et al. 1985 and cross-checked with several industrial experts). The NREU and GHG emissions of converting amorphous PET into $1 \mathrm{t}$ of PET bottles (SSP + bottle moulding) are $23 \mathrm{GJ}$ and $1.4 \mathrm{t} \mathrm{CO}_{2}$ eq. (calculated based on Boustead 2005b and c). Therefore, making bottles is more energy- and GHG-intensive than making fibre. However, the goal of this study is not to compare PET bottles with fibre, but to understand the impact of the recycling system. The fact that making bottles requires more energy than making fibre is not relevant if the recycling systems are compared with the reference system.

${ }^{9}$ In Eqs. 1, 2 and 3, let $X=X_{\mathrm{r}}=650 \mathrm{~kg}$ and $Y=Y_{\mathrm{r}}=350 \mathrm{~kg}$ (thus, $X_{\mathrm{m}}=$ $Y_{\mathrm{m}}=0$, i.e. no make-up V-PET is needed). Since $\eta$ is $95 \%$ and $\varphi$ is $35 \%$, it can be calculated that $b \approx 17 \%$ when $\mathrm{n}$ is $1, b \approx 26 \%$ when $n=2$, $b \approx 31 \%$ when $n=3$ and $b \approx 33 \%$ when $n=4$.
}

3 and 4, respectively). These points represent the recycling systems where no make-up fibre or bottles are needed.

Based on this scenario, we conclude that the impact reduction of the recycling system is sensitive to the choice of the reference system. When the reference system contains more bottles $(650 \mathrm{~kg})$ than fibres $(350 \mathrm{~kg})$, the maximal savings of the recycling system can be achieved when no V-PET is required for make-up purpose, i.e. when the demand of bottles and fibre can be fulfilled by only recycling the used bottles. All these optima are characterised by a maximum of R-PET in the system.

The environmental benefit of recycling originates from producing R-PET to replace V-PET in the system. From this point, we carry the analysis a step further and calculated the energy/GHG-emission savings ${ }^{10}$ per tonne of R-PET produced in the system. The results show a linear relationship between NREU (or GHG emissions) savings and the quantities of R-PET in a recycling system. Thus, impact savings per tonne of R-PET is a constant value, regardless of the scenarios taken, i.e. recycling every tonne of R-PET results in a NREU saving of 43.5 GJ and a GHGemission saving of $2.4 \mathrm{t} \mathrm{CO}_{2}$ eq./t. This value is determined by the credit received from saving V-PET, the penalty received from the recycling process (from bottle collection to pellet production), the credit and penalty received from post-consumer MSWI, and the material efficiency of the recycling process $(\eta)$. A detailed reasoning on this linear relationship can be found in the Electronic Supplementary Material of this paper.

\subsection{Scenario 4: renewably sourced PET}

Figure 8 shows the comparison of four product systems including: the reference system, the baseline recycling system, bio-based PET (single-used system) and recycled

\footnotetext{
${ }^{10}$ NREU (or GHG-emission) saving is defined as the NREU (or the GHG emissions) of the reference system minus the NREU (or the GHG emissions) of the recycling system.
} 
Table 3 Mass balance for different values of $b$ in Scenario 2 (functional unit: $350 \mathrm{~kg}$ of bottles $+650 \mathrm{~kg}$ of fibre; $n=1$; $\mathrm{b}$ is the share of recycled PET pellets used for $\mathrm{B} 2 \mathrm{~B}$ recycling)

\begin{tabular}{|c|c|c|c|c|c|c|c|c|c|}
\hline \multicolumn{2}{|c|}{ (kg per functional unit) } & \multicolumn{7}{|c|}{ Share of bottle waste going to B2B recycling $(b)$} & \multirow[t]{2}{*}{ Reference } \\
\hline & & $0 \%$ & $6 \%$ & $12 \%$ (baseline) & $30 \%$ & $37 \%$ & $50 \%$ & $100 \%$ & \\
\hline A & V-PET (first-life bottle) & 350 & 301 & 263 & 193 & 175 & 148 & 94 & 350 \\
\hline B & V-PET (added to R-bottle) & 0 & 32 & 57 & 102 & 114 & 131 & 166 & 0 \\
\hline $\mathrm{C}$ & V-PET fibre (make up) & 318 & 382 & 431 & 522 & 545 & 579 & 650 & 650 \\
\hline $\mathrm{D}$ & R-PET (used for r-bottle) & 0 & 17 & 30 & 55 & 61 & 71 & 90 & 0 \\
\hline $\mathrm{E}$ & R-PET (used for r-fibre) & 333 & 268 & 219 & 128 & 105 & 71 & 0 & 0 \\
\hline \multirow[t]{3}{*}{$\mathrm{F}$} & Total PC MSWI with ER & 650 & 700 & 737 & 807 & 825 & 852 & 906 & 1,000 \\
\hline & V-PET total $(\mathrm{A}+\mathrm{B}+\mathrm{C})$ & $67 \%$ & $71 \%$ & $75 \%$ & $82 \%$ & $83 \%$ & $86 \%$ & $91 \%$ & $100 \%$ \\
\hline & R-PET total (D+E) & $33 \%$ & $29 \%$ & $25 \%$ & $18 \%$ & $17 \%$ & $14 \%$ & $9 \%$ & $0 \%$ \\
\hline
\end{tabular}

bio-based PET for the functional unit of $650 \mathrm{~kg}$ fibres and $350 \mathrm{~kg}$ bottles. The following results can be observed:

- The system "Recycled bio-based PET" has the lowest impact among all four product systems; it offers at least $35 \%$ of the impact reductions (for both NREU and GHG emissions) compared to the reference system and at least $20 \%$ of impact reductions compared to the baseline recycling system.

- The product system of (virgin) bio-based PET, i.e., without recycling, saves NREU and GHG emissions by $21 \%$ and $25 \%$, respectively, compared to the reference system where petrochemical PET is used (also without recycling).

- The (virgin) bio-based PET system is comparable to the recycled, petrochemical PET system (i.e. the baseline recycling system).

The environmental benefits of bio-based PET and recycled bio-based PET system originate from the low impact of the production of bio-based PET. The cradle-tofactory gate NREU of bio-based PET is $55 \mathrm{GJ} / \mathrm{t}$, which is $17 \%$ lower compared to petrochemical PET. The cradle-to- factory gate global warming of bio-based PET is $1.2 \mathrm{t} \mathrm{CO}_{2}$ eq./t, which is $40 \%$ lower compared to petrochemical PET. In the default case, we assume $50 \%$ sugarcane-based ethanol and 50\% maize-based ethanol for bio-based PET (see Table 2). If only sugarcane-based ethanol or only maize-based ethanol is used, the overall impact changes by less than $\pm 8 \%$. Thus the uncertainty of the bio-based feedstock is small. The overall conclusions on bio-based PET and recycled bio-based PET do not change.

From the results of Scenarios 1, 2 and 3, we understand that the impact of the recycling system can be further reduced by increasing the number of recycling trips (although four trips or more do not contribute to significant additional reduction), maximising the quantity of R-PET in the system, and/or by reversing the functional unit into $650 \mathrm{~kg}$ of bottle and $350 \mathrm{~kg}$ of fibre. These conclusions are also valid for the system "recycled bio-based PET". It can be calculated that the impact of the system "recycled biobased PET" can be further reduced by approximately $50 \%$ if the functional unit is $650 \mathrm{~kg}$ of bottles and $350 \mathrm{~kg}$ of fibre, $n$ is four and $b$ is $33 \%$ (see Fig. 7).

It should be noted that the eco-profile of petrochemical PET has been substantially improved over the last 5 years
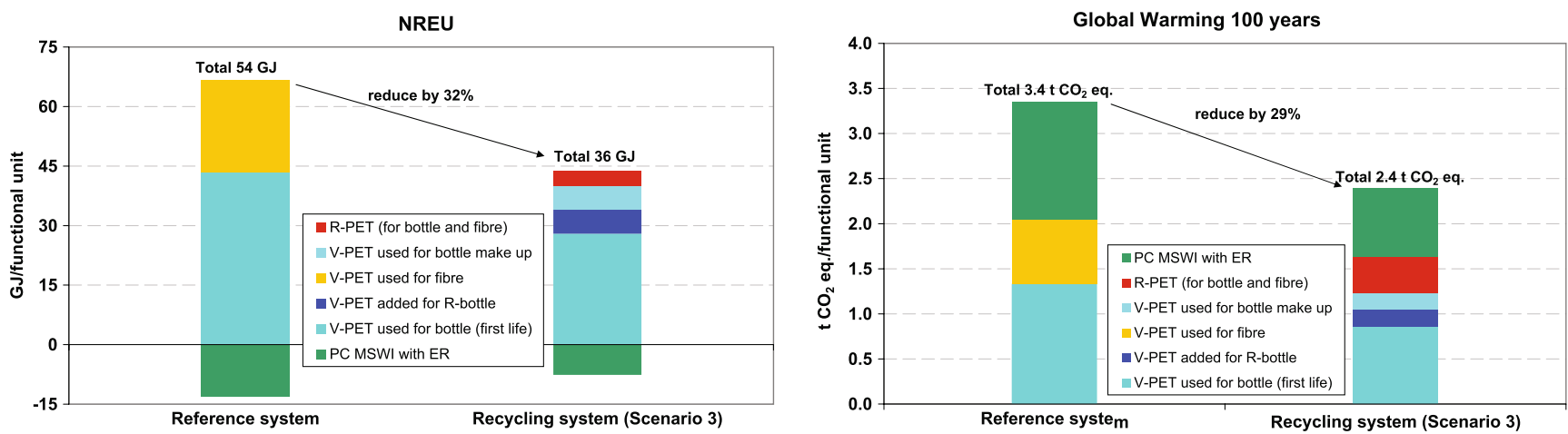

Fig. 6 Cradle-to-grave NREU (left) and global warming (right), functional unit: $650 \mathrm{~kg}$ bottle and $350 \mathrm{~kg}$ fibre in Scenario 3 , with default $b=$ $12 \%$ ( $b$ is the share of recycled PET pellets used for B2B recycling) 
Table 4 Mass balance for different values of $b$ in Scenario 3 (functional unit: $650 \mathrm{~kg}$ bottle $+350 \mathrm{~kg}$ fibre; $n=1$, $\mathrm{b}$ is the share of recycled PET pellets used for $\mathrm{B} 2 \mathrm{~B}$ recycling)

\begin{tabular}{|c|c|c|c|c|c|c|c|c|c|}
\hline \multirow{2}{*}{\multicolumn{2}{|c|}{ (kg per functional unit) }} & \multicolumn{7}{|c|}{ Share of bottle waste goes to B2B recycling (b) } & \multirow[t]{2}{*}{ Reference } \\
\hline & & $0 \%$ & $5 \%$ & $10 \%$ & $12 \%$ (default) & $17 \%$ (minimal) & $50 \%$ & $100 \%$ & \\
\hline A & V-PET (first-life bottle) & 368 & 388 & 409 & 420 & 444 & 276 & 175 & 650 \\
\hline B & V-PET (added to R-bottle) & 0 & 34 & 72 & 90 & 134 & 243 & 309 & 0 \\
\hline $\mathrm{C}$ & V-PET fibre (make up) & 0 & 0 & 0 & 0 & 0 & 219 & 350 & 350 \\
\hline $\mathrm{D}$ & V-PET bottle (make up) & 282 & 210 & 130 & 92 & 0 & 0 & 0 & 0 \\
\hline $\mathrm{E}$ & R-PET (used for r-bottle) & 0 & 18 & 39 & 49 & 72 & 131 & 166 & 0 \\
\hline $\mathrm{F}$ & R-PET (used for r-fibre) & 350 & 350 & 350 & 350 & 350 & 131 & 0 & 0 \\
\hline \multirow[t]{3}{*}{ G } & Total PC MSWI with ER & 632 & 612 & 591 & 580 & 556 & 724 & 825 & 1000 \\
\hline & V-PET total $(\mathrm{A}+\mathrm{B}+\mathrm{C}+\mathrm{D})$ & $65 \%$ & $63 \%$ & $61 \%$ & $60 \%$ & $58 \%$ & $74 \%$ & $83 \%$ & $100 \%$ \\
\hline & R-PET total $(\mathrm{E}+\mathrm{F})$ & $35 \%$ & $37 \%$ & $39 \%$ & $40 \%$ & $42 \%$ & $26 \%$ & $17 \%$ & 0 \\
\hline
\end{tabular}

in Western Europe. The most recently published eco-profile from PlasticsEurope (Liebich and Giegrich 2010) shows that the cradle-to-factory gate NREU and GHG emissions of amorphous PET have been reduced by $17 \%$ and $38 \%$, respectively, compared to the previous eco-profile of PET (Boustead 2005a). The low impact of virgin PET polymer leads to the low impact of PET recycling system. As a result, recycled PET becomes competitive with the virgin bio-based PET.

\section{Sensitivity analysis}

Figure 9 shows the sensitivity of three assumed parameters $\varphi$ (fraction of R-PET content in a recycled bottle), $\eta$ (material efficiency of recycling process), $d$ (the transportation distances assumed, see Table $2, d=d_{1}+d_{2}=400+400=800 \mathrm{~km}$ ) and ER rate of MSWI to the environmental impact of the baseline recycling case. Since the results for global warming are very similar those for NREU, we only present the latter in this section.

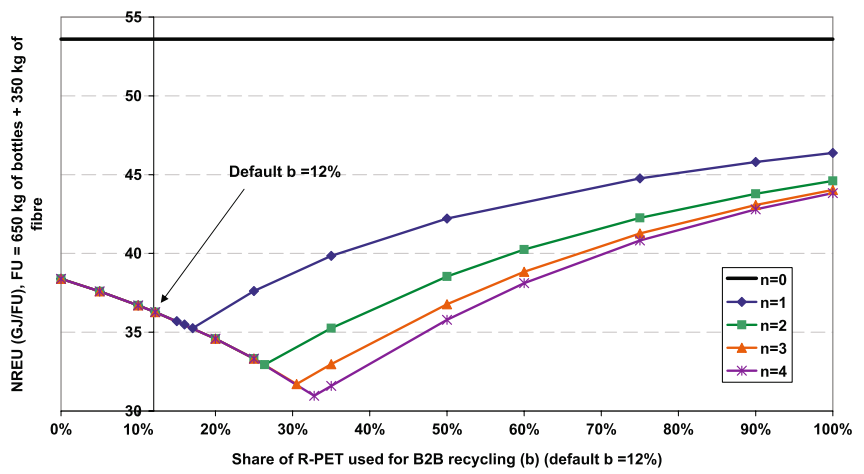

In the LCA, it was assumed that a recycled bottle contains $35 \%$ of R-PET and $65 \%$ of V-PET. If we increase the share of R-PET in the recycled bottle, less V-PET is required. Consequently, the overall impact of the recycling system decreases. When $\phi$ is increased from $35 \%$ to $100 \%$, NREU decreases by less than $5 \%$. Therefore, the sensitivity analysis shows that the impact reduction is not substantial.

In the LCA, it was assumed that $95 \%$ of the used PET can be converted into recycled PET. This assumption was made based on the current industrial practice. Since the material efficiency is a relatively stable parameter in the PET recycling industry, in the sensitivity analysis we slightly change the value of $\eta$, i.e. between $90 \%$ and $97 \%$. A higher material efficiency leads to a lower environmental impact of the recycling system. Figure 9 shows that NREU is not sensitive to the change of $\eta$. When $\eta$ is varied between $90 \%$ and $97 \%$, the change of NREU is less than $\pm 2 \%$.

The third parameter for which the sensitivity was analysed was the transportation distances $(d)$ in PET recycling. In the LCA, a total amount of $800 \mathrm{~km}$ of

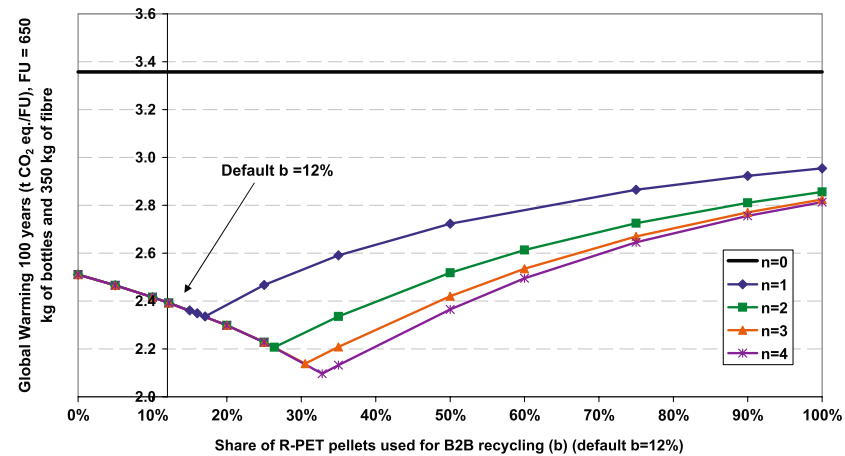

Fig. 7 Effect of changing the share of recycled PET pellets used for B2B recycling $(b)$ in Scenario 3 (left NREU; right global warming) 

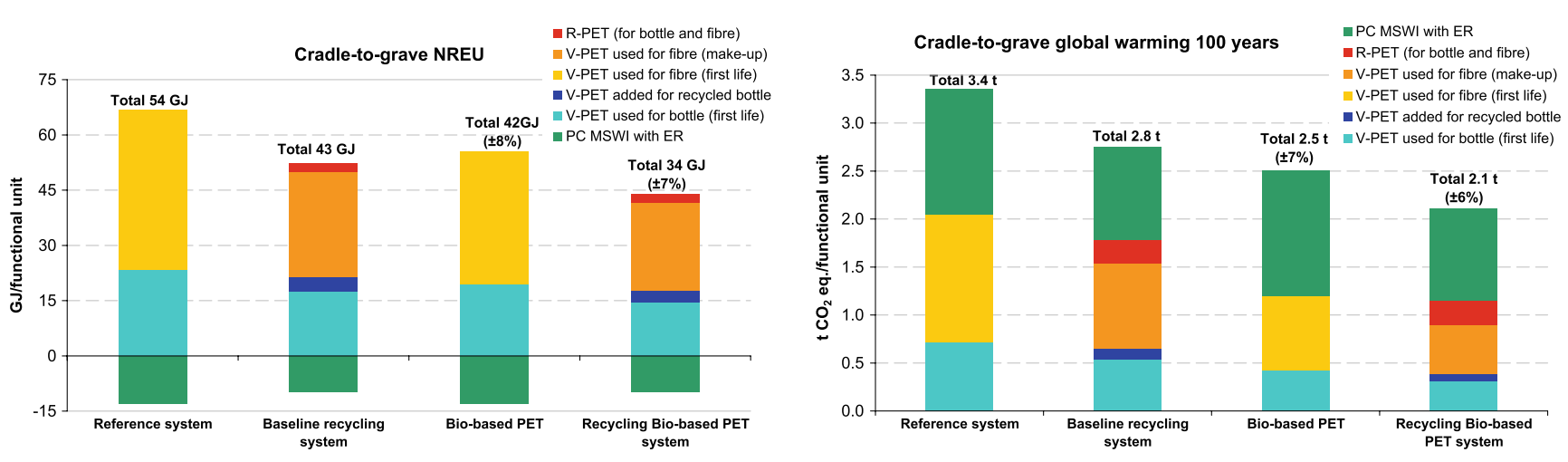

Fig. 8 Cradle-to-grave NREU (left) and Global warming (right) of bio-based PET and recycled bio-based PET, in comparison with reference system and the baseline case; functional unit: $350 \mathrm{~kg}$ of PET bottle $+650 \mathrm{~kg}$ of PET fibre

transportation distance was assumed, including $400 \mathrm{~km}$ for bottle waste collection and $400 \mathrm{~km}$ for flake transportation. When $\mathrm{d}$ is changed between 400 and $1600 \mathrm{~km}$, NREU changes less than $\pm 1 \%$. Therefore, the overall impact is not sensitive to the transportation distance.

In the default analysis, we assumed that the average energy recovery rate of a MSWI plant is $60 \%$ (in primary term, see Table 3). In the sensitivity analysis, we altered the energy recovery rate from $40 \%$ to $80 \%$, representing the changes of $\pm 33 \%$. The result shows that under a very high energy recovery rate $(80 \%)$, the overall NREU decreases by $10 \%$; under a very low energy recovery rate $(40 \%)$, NREU increases by $8 \%$. Thus, the impact is not sensitive to the energy recovery rate of a MSWI.

\section{Conclusions}

Based on the baseline recycling case, four scenarios were built to analyse the change-oriented effects. The main findings of this study are summarised as the following:

1. When comparing the baseline recycling system with the reference system, the environmental impacts (including both NREU and global warming) are reduced by approximately $20 \%$ by the baseline recycling system; the savings mainly originate from the decrease of VPET fibre requirements. Multiple-recycling trips can further reduce the environmental impact of the recycling system by maximally $26 \%$ compared to the reference system. The additional savings become negligible when $n$ is more than three.

2. Based on the reference system where more fibre $(650 \mathrm{~kg})$ is needed than bottles $(350 \mathrm{~kg}), B 2 F$ recycling can achieve greater impact reductions (in both NREU and global warming) than $B 2 B$ recycling; if all R-PET pellets are used to make fibre, the impact of the recycling system reduces to the lowest point, characterised by a maximum of R-PET pellets produced by the system. Increasing the amount of B2B recycling does not bring additional environmental benefits, when the market does not require many bottles.

3. Based on Scenario 3, we conclude that the impact reductions of the recycling system are sensitive to the choice of the reference system. If more bottles $(650 \mathrm{~kg})$ are needed than fibre $(350 \mathrm{~kg})$ in one functional unit, both NREU and global warming are reduced by approximately $30 \%$ for one recycling trip compared to the reference system. A further finding is that the impacts are sensitive to the share of R-PET pellets used for $\mathrm{B} 2 \mathrm{~B}$ and $\mathrm{B} 2 \mathrm{~F}$ recycling. When no extra V-PET is needed for the make-up purpose, the quantities of recycled PET in the system are maximised.

4. Based on the first three scenarios, we conclude that all the optima are characterised by a maximum of R-PET in the system.

5. In Scenario 4, we analysed the role of bio-based PET. Compared to the reference system, the single-used, biobased PET system reduces NREU and global warming by $21 \%$ and $25 \%$, respectively; it is comparable with recycled PET system (the baseline recycling system). The recycling bio-based PET system has the best

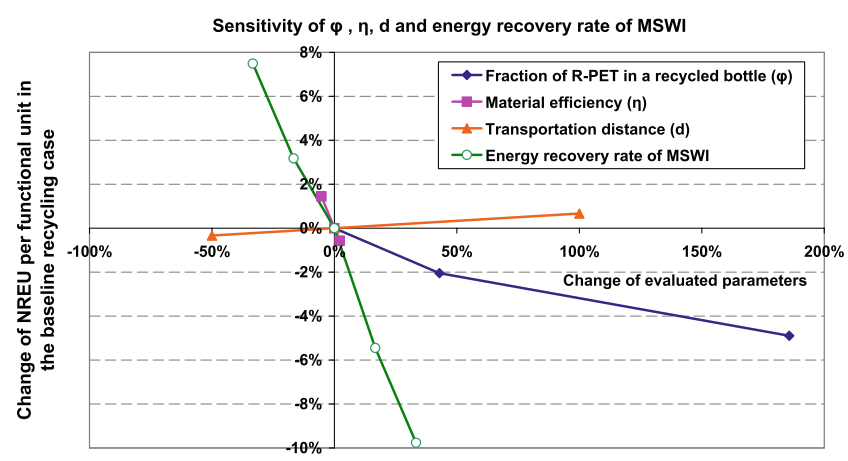

Fig. 9 Sensitivity of the fraction of R-PET in a recycled bottle $(\phi)$, material efficiency of bottle-to-pellet recycling $(\eta)$, transportation distance $(d)$ and energy recovery rate of a MSWI plant in the baseline case 
environmental profile among the four systems studied; it offers 35\% NREU savings and 37\% GHG-emission savings compared to the reference system. Considering the outcome of Scenario 3 we can conclude that the savings would be even larger if bio-based PET were recycled for the purpose of a functional unit of $650 \mathrm{~kg}$ bottles $+350 \mathrm{~kg}$ fibres.

We consider that the uncertainty of the study is small. Most data are collected from peer-reviewed publications or industrial data. Furthermore, the sensitivity analysis shows that results are not sensitive to key assumptions.

In this study, we analysed the effect of certain changes to the PET recycling system. It should be noted that for all four scenarios, we assumed ceteris paribus conditions. For example, the change of the share of R-PET pellets used for $\mathrm{B} 2 \mathrm{~B}$ and $\mathrm{B} 2 \mathrm{~F}$ recycling does not affect the market demand of virgin bottle and fibre, and vice versa. However in reality, the PET material flow is not a static system, but a dynamic one. Further research is recommended to understand the dynamics of PET production and consumption. In that case, dynamic LCA modelling should be applied. It is recommended that other ways of using PET which may lead to a lower environmental impact (e.g. re-use of PET bottles) should be investigated and compared to the recycling approach.

Acknowledgements The authors thank Adidas AG and Lenzing $\mathrm{AG}$, who funded this study. We also are very grateful to David G. M. van der Velden for his contribution to the groundwork of bottle-tobottle recycling.

Open Access This article is distributed under the terms of the Creative Commons Attribution Noncommercial License which permits any noncommercial use, distribution, and reproduction in any medium, provided the original author(s) and source are credited.

\section{References}

Arena U, Mastellone M, Perugini F (2003) Life cycle assessment of a plastic packaging recycling system. Int $\mathrm{J}$ Life Cycle Assess 8 (2):92-98

Bhatt GM (2008) Adding value to recycled pet flakes. Chem Fiber Int 4:223-226

BSI (2008) PAS 2050: Specification for the assessment of the life cycle greenhouse gas emissions of goods and services (Publicly Available Specification). ICS code: 13.020.40. British Standards (BSI)

Boustead I (2005a) Eco-profiles of the European plastics industry polyethylene terephthalate (PET) (amorphous grade). PlasticsEurope, Brussels

Boustead I (2005b) Eco-profiles of the European plastics industry polyethylene terephthalate (PET) (bottle grade). PlasticsEurope, Brussels

Boustead I (2005c) Eco-profiles of the European plastics industry PETbottles. PlasticsEurope, Brussels

Brown HL, Hamel BB, Hedman BA (1985) Energy analysis of 108 industrial processes. U.S. Department of energy, pp 207-209
Chen, GQ, Patel, MK (Forthcoming) Plastics derive $\mathrm{d}$ from biological sources: present and future. Forthcoming in Chemical Reviews

Crank M, Patel MK, Marscheider-Weidemann F, Schleich J, Hüsing B, Angerer G (2005) Techno-economic feasibility of large-scale production of bio-based polymers in Europe (PRO-BIP). Prepared by the Department of Science, Technology and Society/ Copernicus Institute at Utrecht University, Utrecht, Netherlands and the Fraunhofer Institute for Systems and Innovation Research, Karlsruhe, Germany for the European Commission's Institute for Prospective Technological Studies (IPTS), Sevilla, Spain, edited by O. Wolf

Detzel A, Giegrich J, Krüger M, Möhler S, Ostermayer A (2004) Life cycle assessment of PET-OW systems taking into account secondary products. IFEU GmbH, Heidelberg

Doka G (2007) Life cycle inventories of waste treatment services. Ecoinvent report no. 13. Swiss Centre for Life Cycle Inventories, Duebendorf, Switzerland

European Commission (2010) ILCD handbook: General guide for life cycle assessment-provisions and action steps. European Commission, Joint Research Centre, Institute for Environment and Sustainability, Ispra, Italy

Frischknecht R, Jungbluth N, Althaus H-J, Doka G, Dones R, Hellweg S, Hischier R, Humbert S, Margni M, Nemecek T, Spielmann M (2004) Implementation of life cycle impact assessment methods. Final report ecoinvent 2000. Swiss Centre for Life Cycle Inventories, Duebendorf, $\mathrm{CH}$

Glenz W (2007) Polyethylene terephthalate (PET). Kunststoffe 10 (7): $76-80$

Guinée JB (ed) (2001) LCA - an operational guide to the ISOstandards, part 3 scientific background. Institute of Environmental Science (CML), Leiden University, Leiden, NL

Hermann BG, Blok K, Patel MK (2007) Producing bio-based bulk chemicals using industrial biotechnology saves energy and combats global warming. Environ Sci Technol 41(22):79157921

Huijbregts MAJ, Rombouts LJA, Hellweg S, Frischknecht R, Hendriks AJ, van de Meent D, Ragas AMJ, Reijnders L, Struijs J (2006) Is cumulative fossil energy demand a useful indicator for the environmental performance of products? Environ Sci Technol 40(3):641-648

IPCC (2007) 2007 IPCC fourth assessment report (AR4) by working group 1 (WG1), chapter 2 changes in atmospheric constituents and in radiative forcing. Intergovernmental Panel on Global warming (IPCC). http://ipcc-wg1.ucar.edu/wg1/Report/ AR4WG1_Print_Ch02.pdf

Kent R (2008) Energy management in plastics processing framework for measurement, assessment and prediction. Plast Rubber Compos 37:96-104

Kosior E (2007) Food grade recycled PET: technical issues. Waste and Resources Action Program (WRAP), Conference "The opportunity for recycled PET in retail packaging", 6 Feb 2007, London. http://www.wrap.org.uk/document.rm?id=3579

Liebich A, Giegrich J (2010) Eco-profiles of the European plastics industry: Polyethylene terephthalate (PET) (bottle grade). IFEU Institut für Energie- und Umweltforschung Heidelberg $\mathrm{GmbH}$, Heidelberg

Patagonia (2005) Patagonia's common threads garment recycling program: A detailed analysis. http://www.patagonia.com/pdf/ en_US/common_threads_whitepaper.pdf Accessed 18 May 2009

Patel MK, Jochem E, Marscheider-Weidemann F, Radgen P, Thienen Nv (1999) C-ströme, abschätzung der material-, energie- und co2-ströme für modellsysteme im zusammenhang mit dem nichtenergetischen verbrauch, orientiert am lebensweg - stand und szenarienbetrrachtung. FraunhoferInstitut für Systemtechnik und Innovationsforchung (FhGISI), Karlsruhe 
Patel MK, Bastioli C, Marini L, Wurdinger E (2003) Life cycle assessment of bio-based polymers and natural fibre composites. In: Wurdinger E (ed) The encyclopaedia biopolymers, vol 10. Wiley-VCH, pp 409-452

Patel MK, Crank M, Dornburg V, Hermann B, Roes L, Hysing B, van Overbeek L, Terragni F, Recchia E (2005) Medium and longterm opportunities and risks of the biotechnological production of bulk chemicals from renewable resources-the BREW project. Prepared Under the European Commission's GROWTH Programme (DG Research)

Perugini F, Mastellone ML, Arena U (2004) Environmental aspects of mechanical recycling of PE and PET: a life cycle assessment study. Prog Rubber Plast Recy Technol 20(1):69-84

Reimann DO (2006) CEWEP energy report: Results of specific data for energy, efficiency rates and coefficients, plant efficient factors and NCV of 97 European w-t-e plants and determination of the main energy results. Confederation of European Waste-to-Energy plants (CEWEP), Bamberg, Germany

RFA (2010) Climate of opportunity: 2010 ethanol industry outlook. Renewable Fuels Association

Romero-Hernández O, Romero Hernández S, Muñoz D, DettaSilveira E, Palacios-Brun A, Laguna A (2009) Environmental implications and market analysis of soft drink packaging systems in Mexico. A waste management approach. Int J Life Cycle Assess 14(2):107-113

Shen L, Patel MK (2008) Life cycle assessment of polysaccharide materials: a review. J Polym Environ 16(2):154-167

Shen L, Patel MK, Worrell E (2010) Open-loop recycling: a LCA case study of pet bottle-to-fibre recycling. Resour Conserv Recy 55 (1):34-52

Simon C-J, Schnieders F (2009) Business data and charts 2007 by PlasticsEurope market research group (PEMRG). Status September 2008

Song HS, Hyun JC (1999) A study on the comparison of the various waste management scenarios for pet bottles using the life-cycle assessment (LCA) methodology. Resour Conserv Recy 27(3):267-284

Song HS, Moon KS, Hyun JC (1999) A life-cycle assessment (LCA) study on the various recycle routes of pet bottles. Korean J Chem Eng 16(2):202-207

Thiele U (2009) 13th international polyester recycling symposium. Chem Fibres Int 1:22-23

Tillman A-M (2000) Significance of decision-making for LCA methodology. Environ Impact Assess Rev 20(1):113-123

Van der Velden DGM (2010) Life cycle assessment of bottle to bottle recycling. Master thesis NWS-S-2010-14. Department of Science, Technology and Society (STS). Utrecht University, Utrecht 